\title{
Survival of Newly Postmitotic Motoneurons Is Transiently Independent of Exogenous Trophic Support
}

\author{
Clément Mettling, ${ }^{1}$ Annie Gouin, ${ }^{1}$ Michelle Robinson, ${ }^{2}$ Houssein El M'Hamdi, ${ }^{1}$ William Camu, ${ }^{1}$ Evelyne Bloch- \\ Gallego, ${ }^{1}$ Bruno Buisson, ${ }^{1}$ Hideaki Tanaka, ${ }^{3}$ Alun M. Davies, ${ }^{2}$ and Christopher E. Henderson \\ IINSERM U.382, Biochimie CNRS-INSERM, 34033 Montpellier Cedex, France, ${ }^{2}$ School of Biological and Medical \\ Sciences, St. Andrew's, Scotland, and 'Division of Developmental Neurobiology, Kumamoto, Japan
}

\begin{abstract}
We compared the survival requirements of early- and lateborn motoneurons from E5 chicken spinal cord. Density gradient centrifugation followed by immunopanning using SC1 antibody allowed us to purify two size classes of motoneuron. Large motoneurons retained by $6.8 \%$ metrizamide were shown by BrdU labeling in ovo to be born on average $1.5 \mathrm{~d}$ earlier than the small motoneurons recovered from the metrizamide pellet. Large motoneurons were both biochemically and functionally more mature: they expressed higher levels of choline acetyltransferase and lowaffinity neurotrophin receptor, and had an acute requirement for trophic support from muscle-derived factors. After $24 \mathrm{hr}$ in culture in basal medium, all early-born motoneurons died, whereas $60 \%$ of late-born motoneurons survived. Small motoneurons can develop into large motoneurons in ovo, suggesting that they represent a general transitional stage in motoneuron development. Our results suggest that a defined period elapses between birth of a motoneuron and its acquisition of trophic dependence, possibly corresponding to the time required for target innervation. This property may have important consequences for the timing and regulation of developmental motoneuron death.
\end{abstract}

[Key words: chicken embryo, culture of purified motoneurons, neurotrophic factors, SC1, Islet-1, low-affinity neurotrophin receptor, bromodeoxyuridine labeling, trophic dependence]

By the end of the first 2 weeks of embryonic development in the chick, many of the important stages in motoneuron differentiation are already complete (Hamburger, 1977). Following their induction by factors derived from the floor plate and notochord, motoneuron precursors are among the earliest to cease division (Hamburger, 1977; Yamada et a1., 1993). After all have established contact with their target muscle (Landmesser, 1978a), the phase of developmental motoneuron death begins,

Received Aug. 1, 1994; revised Oct. 26, 1994; accepted Nov. 2, 1994

We thank T. Jessell and T. Edlund for the gift of anti-lslet antibody, and R. A. Pollock for help with BrdU staining. We thank the Association Française contre les Myopathies (AFM) and the Institut pour la Recherche sur la Moelle Epinière (IRME) for financial support and for studentships to A.G. and H.E.M. This work was also supported by the Centre National de la Recherche Scienifique, the Institut National de la Santé er de la Recherche Médicale, and the Wellcome Trust

Correspondence should be addressed to C. E. Henderson, INSERM U.382, IBDM, Case 907-Luminy, 13288 Marseille, Cedex 09, France.

Copyright $\odot 1995$ Society for Neuroscience 0270-6474/95/153128-10\$05.00/0 and leads to the loss of approximately half of the motoneurons initially generated (Oppenheim, 1989).

Although these different phases occur sequentially, motoneurons do not enter them synchronously. Postmitotic motoneurons appear in the spinal cord of the chicken embryo between E2.5 and E5 (Hollyday and Hamburger, 1977), and within a given segment motoneuron birth is spread out over as much as $1.5 \mathrm{~d}$. A comparable lack of synchrony is observed for developmental motoneuron death, which in the lumbar spinal cord, for example, extends from E6 to E9 (Hamburger, 1977). Thus, since death of an individual cell is extremely rapid, entry into apoptosis of motoneurons at a given level also seems to be staggered. One possible explanation of the fact that motoneuron birth and death periods are both spread out over several days is that the first motoneurons to be born are also among the first to die. This hypothesis has not been tested in vivo.

How could the lag between motoneuron birth and the onset of cell death be explained? Survival of embryonic motoneurons is regulated by neurotrophic factors derived from the target muscle, but the requirement for such factors seems to vary with age. When a hindlimb bud is removed at E2, massive motoneuron death starts only at E5 and continues over the next $3 \mathrm{~d}$ (Hamburger, 1958; Oppenheim et al., 1978). Thus, motoneurons born at E2.5 are either supported by sources other than muscle until E5, or they acquire a requirement for trophic support only at this stage. The complexity of the in vivo environment makes it difficult to distinguish between these possibilities.

These questions are best answered in vitro, where intrinsic and extrinsic effects on motoneuron survival can be distinguished. However, no method has been described for separating motoneurons on the basis of their birthdate. We hypothesized that, since the size of motoneuron cell bodies increases with embryo age (Oppenheim et al., 1975), earlier-born motoneurons would be larger. Here we show that at appropriately early stages (E5), large and small motoneurons may be physically separated on the basis of their buoyant density and that their birthdates are indeed significantly different. Many late-born motoneurons purified at E5, the beginning of the developmental death period, can survive in culture in the absence of trophic support, whereas early-born motoneurons have an absolute requirement for muscle-derived factors. These results strongly suggest that, as in some sensory systems (Vogel and Davies, 1991), newly postmitotic spinal motoneurons acquire trophic dependency only after a period corresponding to the time necessary for target innervation. 


\section{Materials and Methods}

Cell culture procedures and media. Laminin was purified from the EHS sarcoma; medium supplements and cell culture-tested BSA were from Sigma. All culture media and sera were from Gibco-BRL. "Complete culture medium" was L15 medium, supplemented with sodium bicarbonate $(0.19 \%$, added directly from a $7.5 \%$ stock solution), glucose (20 $\mathrm{mm})$, insulin $(5 \mu \mathrm{g} / \mathrm{ml})$, sodium selenite $(30 \mathrm{nM})$, conalbumin $(0.1$ $\mathrm{mg} / \mathrm{ml})$, progesterone $(20 \mathrm{nM})$, putrescine $(0.1 \mathrm{~mm})$, penicillin $(100$ $\mathrm{IU} / \mathrm{ml})$, and streptomycin $(100 \mu \mathrm{g} / \mathrm{ml})$. "L15-bicarbonate" contained the indicated concentrations of bicarbonate and antibiotics only. Denervated muscle extract from neonatal chicks was prepared as described (Henderson et al., 1983), and stored in aliquots at $-20^{\circ}$ which were thawed only once. Glass coverslips were flamed in $95 \%$ ethanol and incubated overnight at $37^{\circ} \mathrm{C}$ in L15-bicarbonate before use. Substrata were coated with poly-L-ornithine $(1.5 \mu \mathrm{g} / \mathrm{ml}$ in water for $30 \mathrm{~min}$ at room temperature), allowed to dry, and incubated with laminin $(3 \mu \mathrm{g} / \mathrm{ml}$ in L15-bicarbonate) for $3 \mathrm{hr}$ in the $\mathrm{CO}_{2}$ incubator. Immediately before cell culture, the laminin was replaced with fresh culture medium. Cells were seeded at densities of 100 cells in $10 \mu \mathrm{I}$ per Terasaki well (Nunc) and 20,000 cells in $600 \mu \mathrm{l}$ per $16 \mathrm{~mm}$ well.

Preparation of spinal cord dissociates. White Leghorn chicken embryos were incubated at $37.6^{\circ} \mathrm{C}$ for the indicated times. Dissected spinal cords were treated with $0.05 \%$ trypsin in $\mathrm{Ca}^{2+}{ }_{-}, \mathrm{Mg}^{2+}$-free PBS for 15 $\min$ at $37^{\circ} \mathrm{C}$. They were washed with complete serum-free culture medium and resuspended in $1 \mathrm{ml}$ complete medium at room temperature supplemented with BSA $(1 \mathrm{mg} / \mathrm{ml})$ and DNase $(60 \mu \mathrm{g} / \mathrm{ml})$ at a maximum of two spinal cords per tube. After trituration for eight gentle strokes through a Gilson blue cone, any tissue fragments were allowed to settle, the dissociated cells removed, and the fragments dissociated by eight more strokes. Any remaining fragments were rejected. A hemocytometer was used to quantify cell yield and to verify that only single cells were present. As dissociation at E7.5 did not give a homogeneous suspension, the tissue fragments remaining after the first eight strokes were discarded. Although the dissociated cells appeared healthy, they did not develop as well in culture as did motoneurons from earlier stages, so the cells retained by the $6.8 \%$ metrizamide were allowed to attach to a poly-L-ornithine-coated coverslip for $1 \mathrm{hr}$ and processed immediately for double staining.

Preparation of large motoneurons using metrizamide. In order to avoid contamination of panned motoneurons by floor plate, which is also labeled by SC1, spinal cords were subdissected longitudinally using microscissors, generating half-cords, of which only one remained attached to the floor plate. Half-cords were dissociated as described above and cell suspensions (up to four spinal cord equivalents per tube) were loaded on to $1.5 \mathrm{ml}$ cushions of $6.8 \%(\mathrm{w} / \mathrm{v})$ metrizamide (Serva, Heidelberg, Germany) in $\mathrm{L} 15$ medium at room temperature in $10 \mathrm{ml} \mathrm{Ster-}$ ilin polystyrene tubes. Cells were centrifuged for $15 \mathrm{~min}$ at $400 \times \mathrm{g}$ at room temperature with the brake off, then the band of cells at the metrizamide-medium interface was removed in a volume of approximately $1.0 \mathrm{ml}$ and resuspended in $5 \mathrm{ml}$ of $\mathrm{L} 15$ at room temperature. This suspension was layered onto a $1 \mathrm{ml}$ cushion of $4 \%(\mathrm{w} / \mathrm{v})$ BSA (Sigma; cell culture-tested BSA dialyzed overnight at $4^{\circ} \mathrm{C}$ against L15) and centrifuged for $10 \mathrm{~min}$ at $300 \times \mathrm{g}$. The cells in the pellet were resuspended gently in complete culture medium and counted. These are referred to as "large motoneurons."

Purification of small motoneurons by immunopanning. The pellet of small cells that passed through $6.8 \%$ metrizamide (see above) was resuspended in $10 \mathrm{ml} \mathrm{L15}$ and placed in a Petri dish that had been coated with SC1 antibody as described (Bloch-Gallego et al., 1991; Camu et al., 1993). After $45 \mathrm{~min}$ at room temperature, the dish was washed rapidly eight times with PBS and adherent cells were detached by agitation with $3 \mathrm{ml}$ of $\mathrm{SCl}$ hybridoma supernatant containing $15 \%$ fetal calf serum. They were diluted with a further $3 \mathrm{ml}$ of culture medium and collected through BSA cushions as described above. These cells are referred to as "small motoneurons."

Measurement of neuronal survival. Three hours after seeding, initial cell attachment was quantified in 10 low-magnification microscopic fields ( $16 \mathrm{~mm}$ wells) or in at least six independent wells (Terasaki) using a phase-contrast microscope. All phase-bright cells were counted whether or not they had neurites, and this value was taken as $100 \%$ survival. On subsequent days, cells with neurites more than two cell diameters in length were counted in the same fields; their number was expressed relative to the initial value for the same well.

Immunostaining of neuronal cultures. Living culturcs to be staincd with $\mathrm{SC1}$ or $\mathrm{M} 7412$ antibodies were incubated for $30 \mathrm{~min}$ in the $\mathrm{CO}_{2}$ incubator with a 10-fold dilution of the hybridoma supernatant. After liree gentle washes with L15 medium, they were fixed for 30 min at room temperature using $4 \%$ paraformaldehyde (PFA) in $0.1 \mathrm{M}$ phosphate buffer, $\mathrm{pH}$ 7.4. After two washes with PBS and a $30 \mathrm{~min}$ incubation in PBS/2\% BSA, subsequent incubations were with biotinylated anti-mouse IgG (Amersham; 1:100) and streptavidin-fluorescein (Bethesda Research Labs; 1:100) or streptavidin-horseradish-peroxidase (Amersham; 1:500). Fluorescent cells were mounted in Citifluor and photographed using a Nikon Microphot FXA. Cultures to be stained with the anti-Islet-1 monoclonal antibody 4D5 were fixed for $20 \mathrm{~min}$ with ice-cold 4\% PFA in PBS. After three washes, cells were incubated for $10 \mathrm{~min}$ in $50 \mathrm{~mm}$ lysine and $0.1 \%$ Triton X-100 in PBS, then for $30 \mathrm{~min}$ in PBS containing $10 \%$ horse serum, $2 \% \mathrm{BSA}$, and $0.1 \%$ Triton. The first antibody was incubated $1 \mathrm{hr}$ at room temperature at 1:200 in the same buffer, followed by FITC- or Cy3-coupled anti-mouse antibody (Sigma; 1:100). For BrdU detection, labeled cells were fixed with $4 \% \mathrm{PFA}$, and histones were removed using $2 \mathrm{M} \mathrm{HCl}$ for $60 \mathrm{~min}$ at room temperature. After two washes with L15-bicarbonate and two with PBS, anti-BrdU fluorescein antibody (Boehringer clone BMC 9318;1:100) was added for $1 \mathrm{hr}$ at room temperature. The double-labeling experiment shown in Figure 3 was done by first following the Islet-1 procedure with a second antibody coupled to rhodamine. After fixation for $10 \mathrm{mn}$ with $4 \% \mathrm{PFA}, \mathrm{HCl}$ was added before applying the anti-BrdU antibody.

$B r d U$ injection. For the experiment shown in Figure 4, $100 \mu l$ of the indicated concentrations of BrdU (Boehringer) in L15 were dropped onto the choriallantoid membrane in ovo at $48 \mathrm{hr}\left(100^{\circ} \mu \mathrm{M}\right), 72 \mathrm{hr}(200$ $\mu \mathrm{M}), 96 \mathrm{hr}(1 \mathrm{mM})$, and $120 \mathrm{hr}(1 \mathrm{~mm})$ of incubation. Injections made on a given day were always followed by injection at the subsequent time points, so as to prevent BrdU dilution. The concentrations used were determined in preliminary experiments to be the maximum sublethal dose at each stage. Spinal cords were dissected at $132 \mathrm{hr}$ (E5.5) of incubation

Assay for choline acetyltransferase (ChAT). Choline acetyltransferase activity was measured by a modification of the method of Fonnum (1975). Briefly, cell homogenates were prepared by trituration in $0.2 \%$ Triton X-100 and $0.2 \mathrm{M} \mathrm{NaCl}$, and stored at $-20^{\circ} \mathrm{C}$. Small volumes $(10$ $\mu$ ) of homogenate were incubated with an equal volume of assay cocktail containing ${ }^{3} \mathrm{H}$-acetyl coenzyme $\mathrm{A}$ for $20 \mathrm{~min}$, then the reaction was stopped and toluene-soluble radioactivity was counted using a scintillation counter. Background samples in which cell homogenate was replaced by extraction buffer routinely gave less than $5 \%$ of maximal values; all measured activities were corrected by subtraction of background. Incubation with acetylcholinesterase in the absence of eserine typically reduced recovered radioactivity by $95 \%$.

Measurement of $p 75^{N G F-R}$ mRNA in motoneuron populations. A quantitative RT-PCR technique was used to measure p75 mRNA in small and large motoneurons, as described in detail elsewhere (Allsopp et al., 1993). Briefly, this technique uses two internal controls: the ratio between signals corresponding to p75 and the ubiquitous, constitutively expressed L27 ribosomal protein controls for the efficiency of the mRNA extraction, and the addition of a slightly larger p75 or L27 RNA standard to the RNA preparation controls for the efficiency of the reverse transcription and amplification steps. The level of each mRNA was determined by densitometrically comparing the relative intensities of the mRNA and RNA standard amplification products on autoradiographs. The results are expressed as the quotient of the amount of p75 and L27 mRNAs extracted for small and large motoncurons.

\section{Results}

Two distinct populations of motoneuron are simultaneously present in $E 5$ chicken spinal cord

To separate developing motoneurons on the basis of their size, we used the metrizamide density centrifugation method, which enriches for large cells on the basis of their lower buoyant density (Schnaar and Schaffner, 1981; Dohrmann et al., 1986, 1987; Arakawa et al., 1990; Comella et al., 1994). In dissociates of embryonic chicken spinal cords prepared at E4.5 or before, no cells were retained by $6.8 \%$ metrizamide (not shown). We thercfore measured the diameter of freshly dissociated total spinal cord cells over the subsequent days (Fig. 1A). At E5, E6, and E7, dissociates contained a majority of smaller cells $(<10 \mu \mathrm{m})$, 

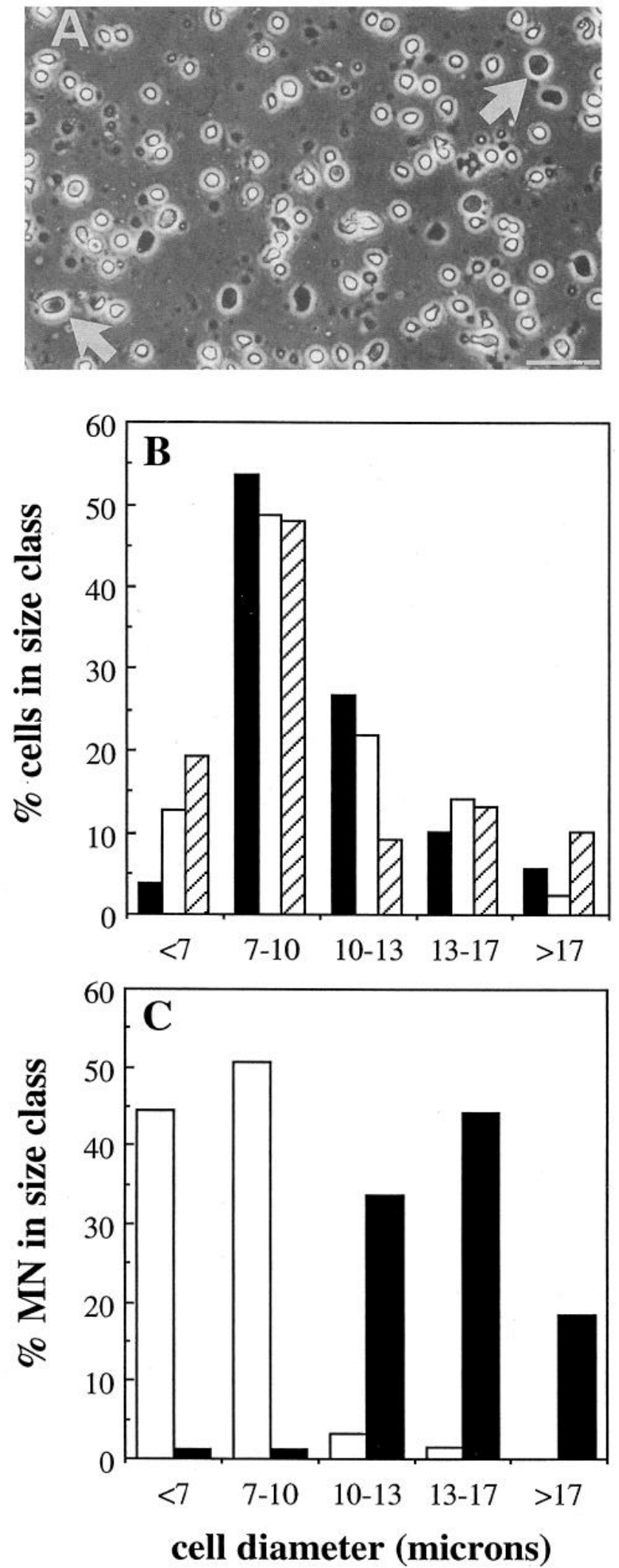

Figure 1. Two classes of motoneuron are simultaneously present in E5 chicken spinal cord. A, Phase-contrast micrograph of dissociated cells from total $5 \mathrm{~d}$ (stage 26) spinal cord. A subpopulation of larger cells (arrowheads) is clearly apparent. Scale bar, $50 \mu \mathrm{m}$. B, Histogram of size distributions for lumbar spinal neurons from $5 \mathrm{~d}$ (stage 26; filled bars), 6 d (stage 29; open bars), and 7 d (stage 31; hatched bars) chicken embryos. The bin labeled 7-10 $\mu \mathrm{m}$ includes those cells with a
Table 1. Rostrocaudal distribution of large and small motoneurons

\begin{tabular}{lll}
\multirow{2}{*}{$\begin{array}{l}\text { Region of } \\
\text { E5 spinal cord }\end{array}$} & \multicolumn{2}{l}{ Motoneuron yield $(\%$ of total dissociated cells $)$} \\
\cline { 2 - 3 } & Large motoneurons & Small motoneurons \\
\hline Cervical & $3.6 \pm 0.8$ & $0.9 \pm 0.4$ \\
Brachial & $3.6 \pm 0.8$ & $1.3 \pm 0.4$ \\
Thoracic & $2.8 \pm 0.5$ & $0.5 \pm 0.1$ \\
Lumbar & $3.1 \pm 0.6$ & $1.0 \pm 0.3$
\end{tabular}

Cervical (segments 5-10), brachial (segments 14-17), thoracic (segments 1922), and lumbar (segments 24-29) regions of spinal cords from E5 chicken embryos were subdissected and used separately to prepare large and small motoneurons by the metrizamide-panning method. The number of cells obtained was expressed as a percentage of the total number loaded onto the metrizamide cushion. Results are expressed as mean \pm SEM ( $n=2-5$ independent experiments). Yields of small motoneurons may underestimate their true abundance relative to large motoneurons, as additional steps are involved in their purification.

but also a significant number of larger cells $(>10 \mu \mathrm{m})$ (Fig. $1 B)$. The proportion and absolute size of the latter was nearly constant. Given that motoneuron abundance should actually decrease during this period as a result of motoneuron death and continuing proliferation of other spinal cells, this suggested that fractions of large cells from older embryos contained more nonmotoneurons. We therefore decided to use the metrizamide gradient method at the earliest stage $(5 \mathrm{~d})$ at which we observed clear differences in cell size.

Spinal cords from $5 \mathrm{~d}$ chicken embryos were subdissected to remove floorplate, dissociated, and fractionated by centrifugation over $6.8 \%$ metrizamide cushions. The band of cells remaining above the cushion was collected by centrifugation. Typically, 35,000 cells per half-embryo (see Materials and Methods) were obtained by this procedure, representing approximately $3 \%$ of total cells in the spinal cord dissociate. After $20 \mathrm{hr}$ in culture on polyornithine-laminin in the presence of muscle extract to allow regeneration of surface antigens, the cultures were labeled using antibodies to the motoneuron markers SC1 (Fig. 2A) and Islet-1 (Fig. 2C,E). At this stage, both $\mathrm{SCl}$ and Islet-1 antibodies apparently label all motoneurons (Ericson et al., 1992). Of neurons purified in this manner, $90 \pm 2 \%(n=8$ experiments) were $\mathrm{SC} 1$ positive and $81 \pm 6 \%(n=6)$ stained for Islet- 1 . A fraction (ca. $10 \%$ ) of cells that were dense enough to pass through the metrizamide cushion were also found to be SC1-positive neurons (not shown). This second population was therefore further purified by immunopanning on SC1 antibody (Bloch-Gallego et al., 1991; Camu et al., 1993). The yield of these cells was approximately 20,000 per half-embryo; they were $95 \pm 2 \%$ enriched for SC1-labeled neurons (Fig. $2 B$ ) and $65 \pm 2 \%$ for Islet1-positive neurons (Fig. 2D,F), suggesting that they too represented a highly enriched population of motoneurons.

The size distribution of the cells in each motoneuron preparation was measured before seeding (Fig. $1 C$ ). The average diameter of the motoneurons retained by $6.8 \%$ metrizamide was $13.8 \pm 0.3 \mu \mathrm{m}$ (SEM; $n=77$ ), as reported by others (Comella et al., 1994), and that of the panned cells from the metrizamide

$\leftarrow$

diameter included in the range 7.1-10.0 $\mu \mathrm{m}$. The fraction of large cells does not significantly change over this period. $C$, Histogram of size distribution of large motoneurons retained by $6.8 \%$ metrizamide cushions (solid bars) compared with small motoneurons (open bars) purified by immunopanning from the metrizamide pellet. 

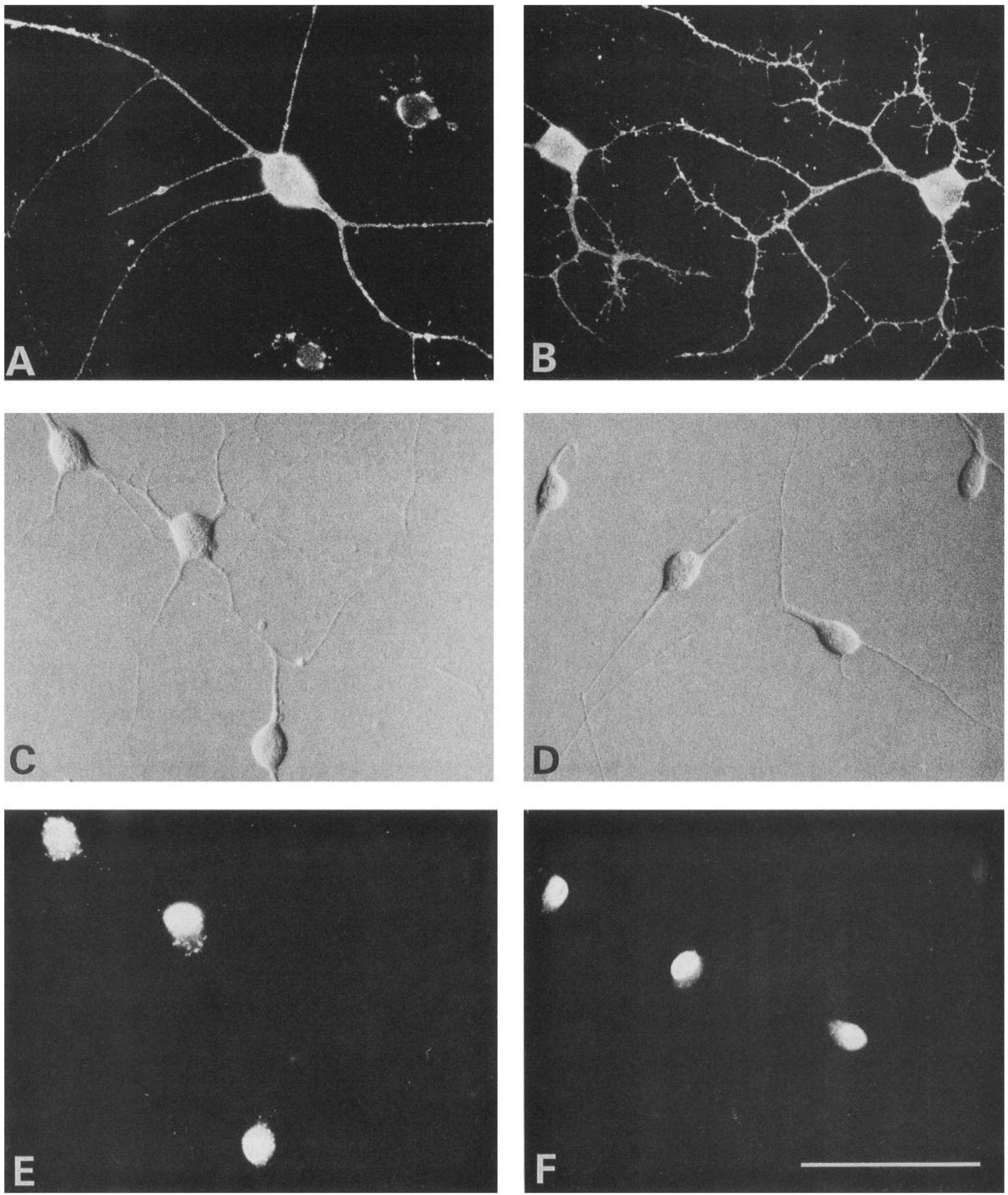

Figure 2. Estimation of purity of the "large" and "small" motoneuron populations using antibodies to the motoneuron markers SC1 and Islet-1. Immunofluorescence labeling of large $(A, C, E)$ and small $(B, D, F)$ motoneurons after $1 \mathrm{~d}$ in culture on a polyornithine-laminin substratum in the presence of $25 \mu \mathrm{g} / \mathrm{ml}$ muscle extract. Cells were stained using monoclonal antibodies to SC1 $(A, B)$ or Islet-1 $(E, F)$. $C$ and $D$, Same cells as in $E$ and $F$ viewed using differential interference contrast optics. Note the Islet-1-negative neuron in $D$. Scale bar, $50 \mu \mathrm{m}$. 

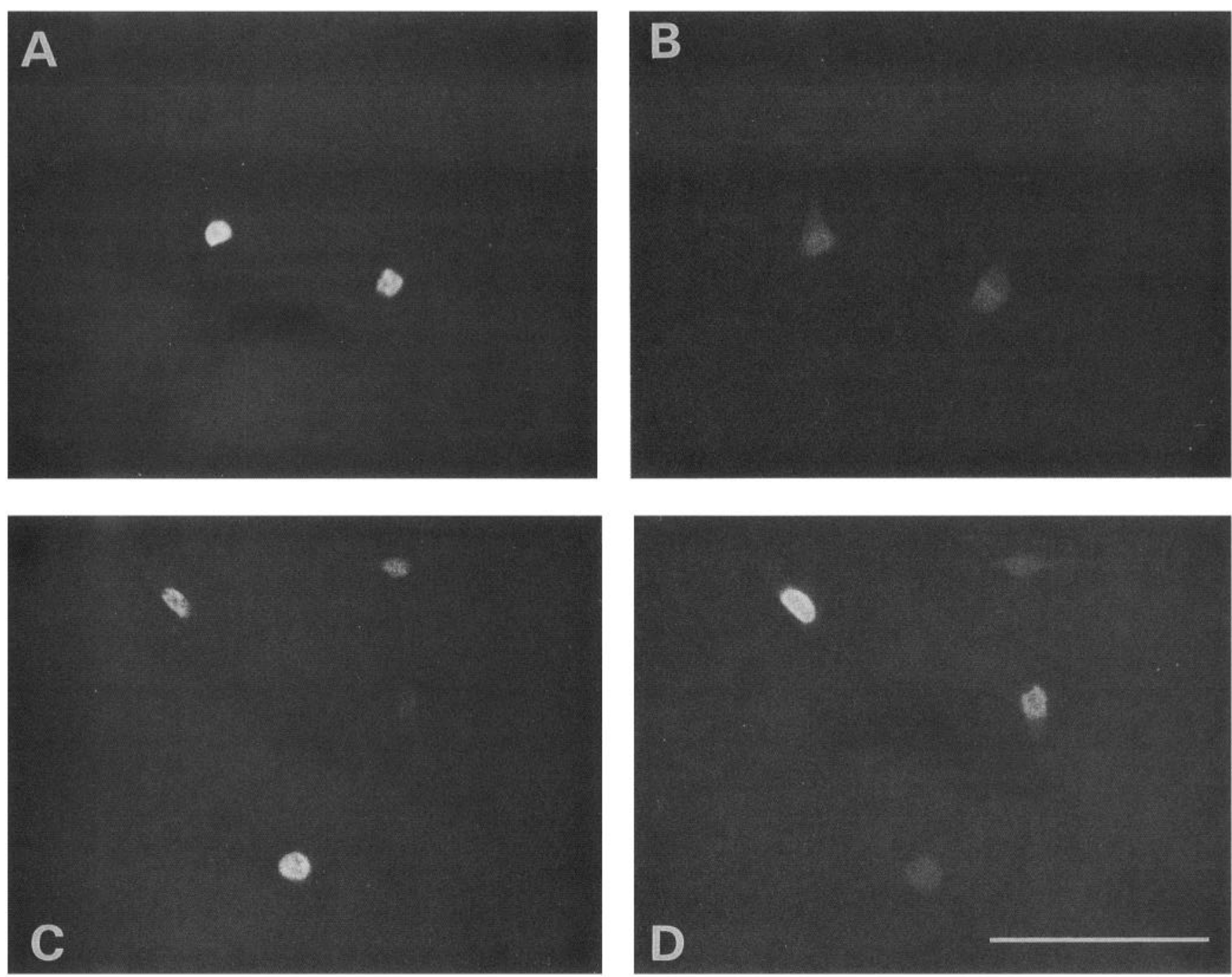

Figure 3. Determination of motoneuron birthdate by BrdU incorporation. Large $(A, B)$ and small $(C, D)$ motoneurons were purified at E5.5 from a chick embryo injected with BrdU at E4 and E5. Double labeling using antibodies to Islet-1 $(A, C)$ and $\mathrm{BrdU}(B, D)$ is shown; only nuclei are labeled. Note the small Islet-1-positive motoneuron that has incorporated BrdU during the fifth day of embryonic development $(C, D)$. Scale bar, $50 \mu \mathrm{m}$.

pellet was $6.5 \pm 0.2 \mu \mathrm{m}(n=66)$; very little overlap in the size distribution was observed (Fig. $1 C$ ). We shall therefore refer to the former as "large motoneurons" and to the latter as "small motoneurons."

To ascertain that the large motoneurons did not simply represent more rostral neurons that had differentiated earlier, cervical, brachial, thoracic, and lumbar sections of spinal cord were dissected and submitted to the metrizamide-panning procedure. The relative yield of large motoneurons did not vary significantly between the different levels (Table 1). In particular, large motoneurons were not restricted to the lateral motor columns of the limb segments. Small motoneurons were abundant in limb segments, demonstrating that they are not preganglionic sympathetic neurons, whose precursors are potentially labeled by SC1 and Islet-1 (Tanaka and Obata, 1984; Ericson et al., 1992) but are absent from brachial and lumbar regions of the spinal cord (Oppenheim et al., 1989).

As expected from the size histograms of spinal cord dissociates (Fig. $1 B$ ), the metrizamide step gave less enrichment for motoneurons at later stages. Using total spinal cord at E6, only
$55 \pm 3 \%(n=5)$ of the cells retained by $6.8 \%$ metrizamide were stained by SC1 antibody, and at later stages even lower values were obtained (not shown).

\section{Large motoneurons are born earlier than small motoneurons}

The mean birthdate of the large and small motoneuron populations at E5 was investigated by mitotic labeling. As pulse labeling is not possible in ovo (Hollyday and Hamburger, 1977), BrdU was injected every $24 \mathrm{hr}$ starting at different embryonic ages, and spinal cords were dissected at E5.5. Motoneurons that were postmitotic at the time of injection were thus unlabeled. The choice of E5.5 as the age of dissection was dictated by two considerations: (1) BrdU injection slightly slowed development, meaning that in embryos that had been treated for several days not enough motoneurons were large enough at E5 to be retained on the metrizamide cushion; and (2) to obtain values for mitotic index at E5 required leaving the embryos longer to allow for diffusion and incorporation of the BrdU. A secondary consequence of using slightly older embryos (see above) was that the purity of the large and small motoneuron preparations was lower 


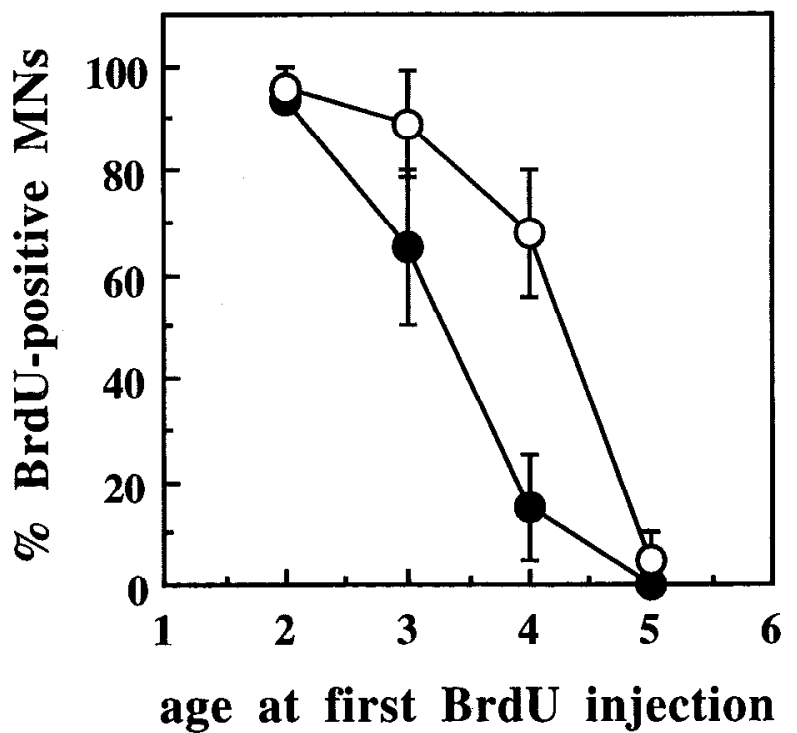

Figure 4. Large and small motoneurons have different birthdates. BrdU was applied daily to chicken embryos starting on the indicated embryonic day. Large $(O)$ and small $(O)$ motoneurons were purified from each embryo at E5.5, cultured overnight, and then double labeled for Islet-1 and BrdU. Counts were expressed as the percentage of Isletpositive neurons in each preparation that had incorporated BrdU. Values are expressed as mean \pm range of $2-4$ independent experiments.

than for E5 embryos $(63 \pm 5 \%$ and $56 \pm 5 \%$ Islet-1-positive neurons, respectively; $n=6$ ). To take this into account, the mitotic index was assessed as the percentage of Islet-1-positive neurons labeled by BrdU. This was counted directly in doublelabeled preparations (Fig. 3).

Daily injections of BrdU starting at E2 labeled essentially all large and small motoneurons, as expected (Fig. 4) (Hollyday and Hamburger, 1977). By E3, nearly $40 \%$ of large motoneurons are born. The most striking difference between the populations is seen at $\mathrm{E} 4$, at which stage $85 \%$ of the large motoneurons are already postmitotic, whereas nearly $70 \%$ of the small motoneurons have yet to be born. The majority of small motoneurons are therefore born in the $24 \mathrm{hr}$ preceding normal motoneuron purification at E5. Only very rare motoneurons were labeled by a single injection at E5. This cannot be explained by a delay between injection and incorporation of the BrdU, as the same injection at E5 labeled $30 \%$ of the total spinal cord cells, presumably corresponding to later-maturing neuronal and glial populations. These results confirm that motoneurons born early and late within the period of motoneuron generation can indeed be separated clearly on the basis of their size, and that most of the small motoneurons are newly postmitotic.

\section{Large motoneurons are biochemically more mature than small motoneurons}

Levels of choline acetyltransferase (ChAT) activity are relatively low in early motoneurons and increase during development (Phelps et al., 1990). To determine whether small and large motoneurons represented different stages of maturation, we measured ChA' activity in freshly dissociated motoneurons. In a typical experiment, radioactivity incorporated into acetylcholine by the contents of $10^{5}$ small and large motoneurons, respectively, was $4460 \mathrm{dpm}$ and $13,515 \mathrm{dpm}$, representing a threefold higher specific ChAT activity in large motoneurons.

Another molecule whose expression in motoneurons increases over the period leading up to the beginning of cell death is the low-affinity neurotrophin receptor, p75NGF-R (Raivich et al., 1985; Yan and Johnson, 1987). Although the biological role of this molecule on chick motoneurons at this stage is not clear (Arakawa et al., 1990; Oppenheim et al., 1992; Henderson et al., 1993), we used it as a marker for early motoneuron maturation. Using the monoclonal antibody M7412 (Tanaka et al., 1989), which recognizes the chicken p75 (H. Tanaka and B. Buisson, unpublished results) and stains motoneurons in early embryonic spinal cord, cultures of small and large motoneurons were labeled with M7412 after $1 \mathrm{~d}$ in culture (Fig. 5A,B). Although many cells in each population showed specific labeling, staining of large motoneurons was significantly more intense (Fig. $5 B$ ). We confirmed this finding using a quantitative RTPCR assay for chicken p75 mRNA (Fig. 5C,D) on freshly prepared suspensions of large and small motoneurons from E5 embryos. Expressed relative to the control L27 mRNA, large motoneurons contained on average 2.5-fold higher levels of $\mathrm{p} 75$ mRNA (Fig. 5D). These results demonstrate that by E5 earlyborn motoneurons are biochemically more mature than ncwly postmitotic motoneurons.

\section{Trophic dependence of large and small motoneurons}

The increased levels of low-affinity neurotrophin receptor on large motoneurons suggested that they might also be functionally more mature. We therefore compared their need for trophic support with that of the small motoneurons. Large and small motoneurons were seeded at low density in complete culture medium with supplements but in the absence of muscle extract. They were counted $3 \mathrm{hr}$ after seeding and then at daily intervals. Their behavior was strikingly different: at low density (30 cells/well) in Terasaki wells, virtually all large motoneurons died within $24 \mathrm{hr}$, whereas $>30 \%$ of small motoneurons survived for $2 \mathrm{~d}$ (Fig. 6A). The delay in the death of small as compared to large motoneurons, measured as the separation between the curves, was 1-2 d. $\Lambda$ comparable difference was observed at higher density: when 20,000 motoneurons of each class were seeded in $16 \mathrm{~mm}$ wells, only $15 \%$ of large motoneurons survived for $2 \mathrm{~d}$ in culture, whereas $42 \%$ of small motoneurons were still alive after $4 \mathrm{~d}$. The rapid death of large motoneurons was unlikely to result from the method of preparation, as small motoneurons underwent more purification steps. Nevertheless, we subjected large motoneurons to immunopanning on SC1: they still died rapidly (not shown). In order to confirm that the small neurons that survived in basal medium were indeed motoneurons, neurons grown at 10,000 cells/well were stained for Islet- 1 after different times in culture. After $4 \mathrm{~d}$ of culture in basal medium, $54 \%$ of Islet-1-positive small motoneurons survived, whereas the corresponding figure in cultures of large motoneurons was only $6 \%$; the relative abundance of Islet-1-positive neurons remained constant in each case.

We compared the ability of each population to respond to trophic support. Since the precise neurotrophic factors involved in the chicken system are not well understood, we used denervated muscle extract, which has been shown to have the widest range of protective actions (and the highest efficacy) on chicken motoneurons in ovo (Oppenheim et al., 1993). Muscle extract did not enhance cell attachment (not shown), but after only $1 \mathrm{~d}$ in culture, a dose-dependent cffect of muscle extract on survival of both populations was evident (Fig. 6B). However, survival of large motoneurons in optimal concentrations of muscle extract was sixfold higher than that in basal medium, reflecting their 

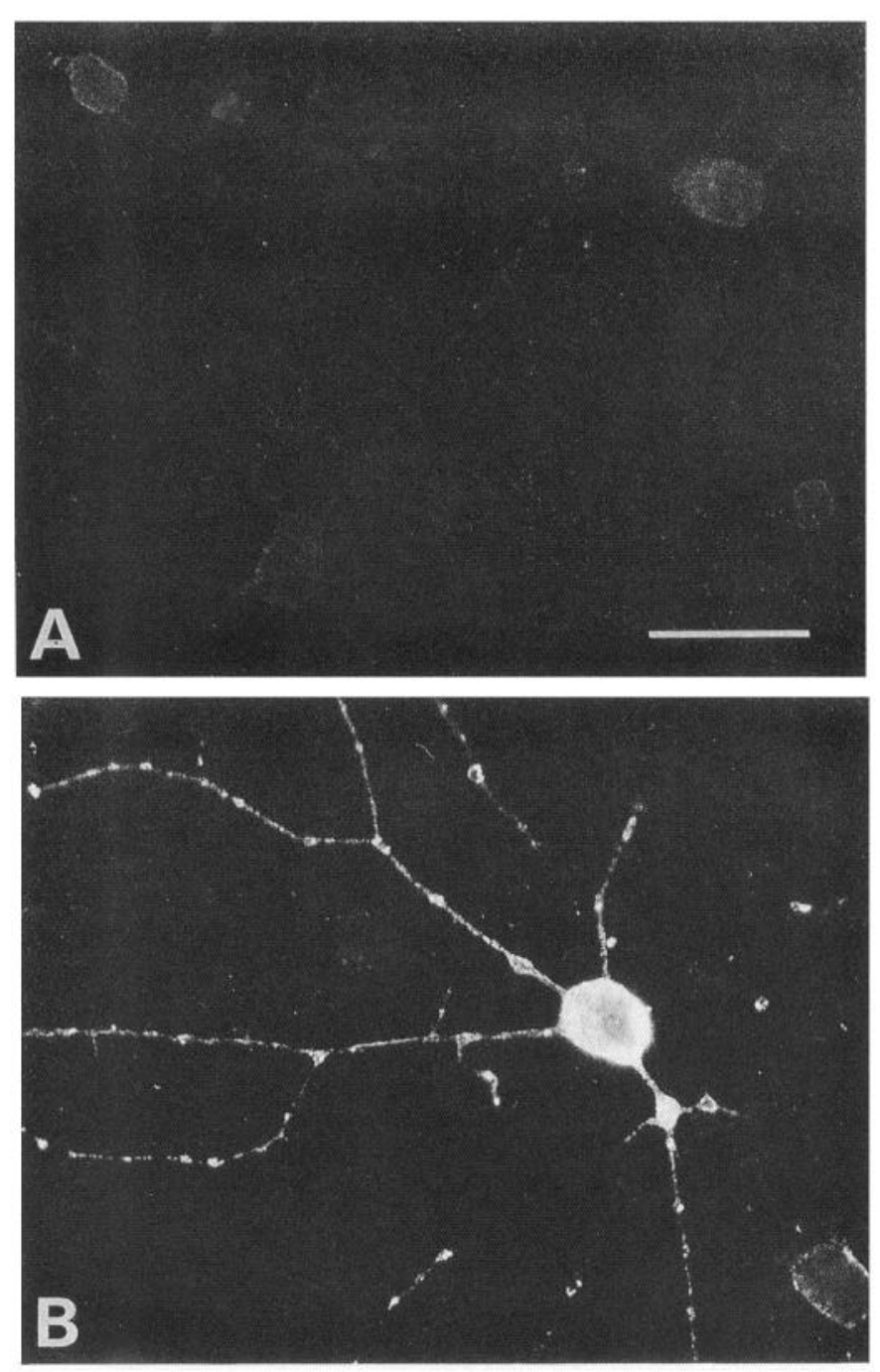

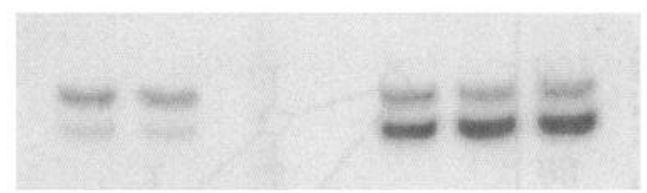

$\begin{array}{lllllll}1 & 2 & 3 & 4 & 5 & 6 & 7\end{array}$

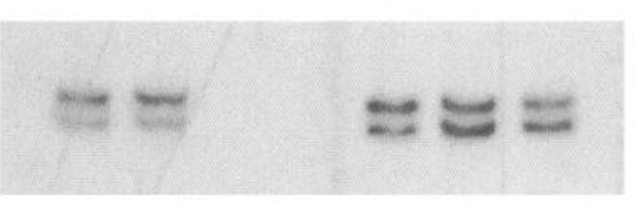

C

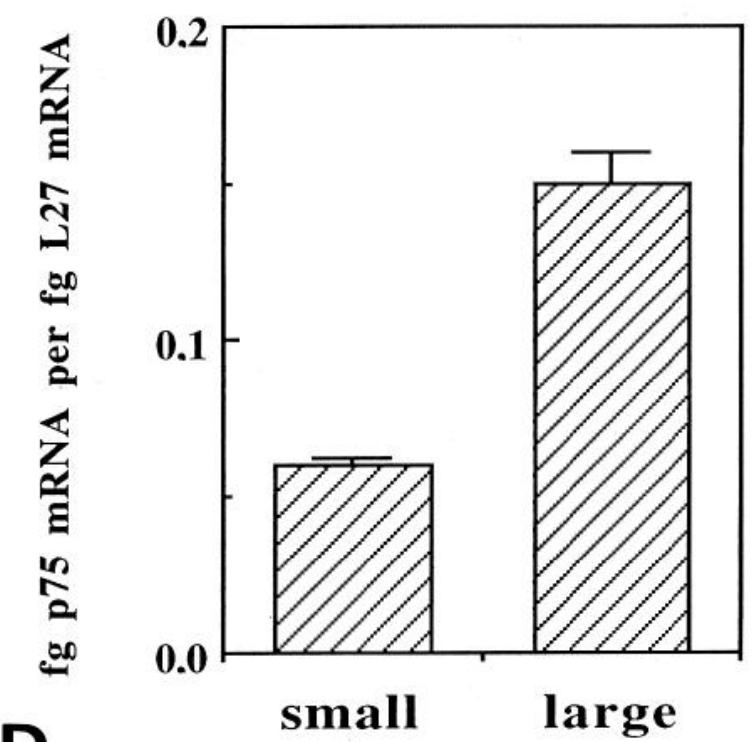

Figure 5. Large motoneurons express higher levels of low-affinity neurotrophin receptor. $A, B$, Immunofluorescence labeling using the M7412 monoclonal antibody, which recognizes the chicken p75NGF-R. Photographs of small $(A)$ and large $(B)$ motoneurons labeled and photographed in identical conditions are shown. Scale bar, $25 \mu \mathrm{m}$. $C$, Quantitative RT-PCR on mRNA extracted from two independent small motoneuron samples (lanes 1, 2) and three independent large motoneuron samples (lanes 5-7). Controls without RTase are shown in lanes 3 and 4 . Amplified fragments obtained using p75 (upper gel) and L27 control primers (lower gel) are shown. On each gel, the lower band represents amplification of the mRNA and the upper one the amplification of the RNA recovery standard. $D$, Quantification of relative levels of p75 mRNA by densitometry of the autoradiographs shown in $C$.

acute requirement for trophic support. The variation in small motoneuron survival was only 1.4-fold over the same range of muscle extract concentrations. The dose-response curve for large motoneurons could not be completed in these low-density cultures, as higher concentrations of muscle extract were toxic. However, at higher density, $83 \%$ of large motoneurons survived for $4 \mathrm{~d}$ in culture in the presence of muscle extract and only $13 \%$ in its absence, demonstrating that most of the large motoneurons are indeed viable and responsive to muscle extract.

\section{Small motoneurons are precursors of large motoneurons}

It was formally possible that the early- and late-born motoneuron populations that we had separated were independent, and did not represent general stages in the early maturation of spinal motoneurons. We used both in vitro and in vivo methods to demonstrate that at least a fraction (and probably all) of the small motoneurons are indeed developmental precursors of the large population.
We first determined whether small motoneurons could mature functionally in vitro in the presence of muscle extract so as to acquire the trophic dependence of large motoneurons. It was not feasible to replace muscle extract with basal medium after different periods of culture, as (1) the time period involved was too short and (2) the trophic components of muscle extract remain bound to the laminin substratum in these conditions (A. Gouin and C. E. Henderson, unpublished results). We therefore compared the responsiveness to muscle extract of large motoneurons after $2 \mathrm{~d}$ of culture to that of small motoneurons after 3 d. The two dose-response curves are superimposable (Fig. 7), and only slightly different from the curve for large motoneurons at $1 \mathrm{~d}$ of culture (Fig. 6B). These results suggest that small motoneurons acquire trophic responsiveness in culture approximately 1-2 d later than large motoneurons, in agreement with the data of Figure $6 A$ and the difference in their birthdates (Fig. 4).

To follow the fate of the small motoneuron population in ovo, 

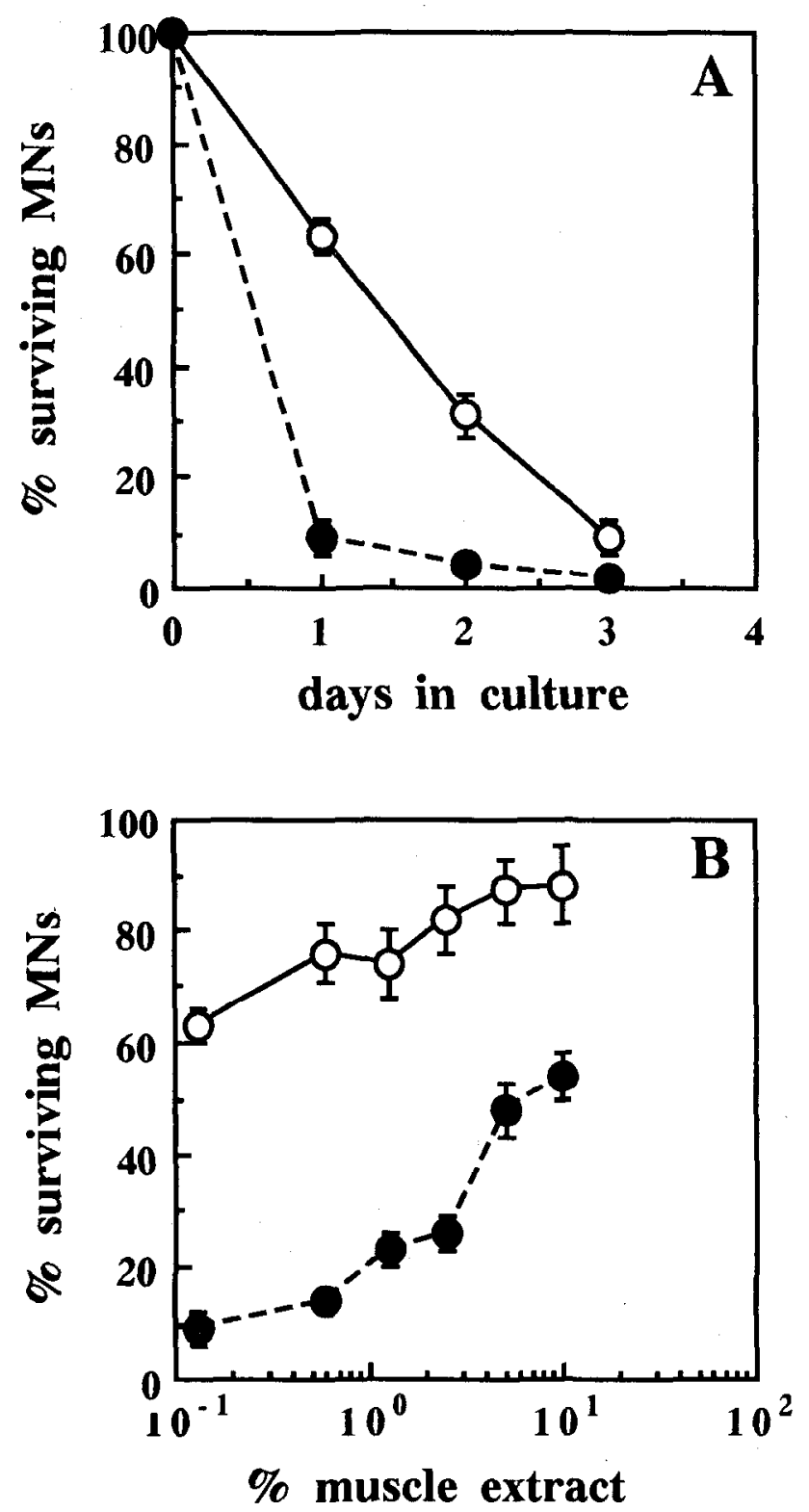

Figure 6. Newly postmitotic motoneurons show less trophic dependence than earlier-born motoneurons. A, Small motoneurons show delayed death in the absence of trophic support. Large (O) and small (O) motoneurons were seeded in Terasaki wells in complete culture medium without muscle extract. Surviving neurons were counted at the indicated times; values were expressed relative to the number that attached to the dish after 4 hr. $B$, Muscle extract has proportionally less effect on small than on large motoneurons. Large $(\mathbf{O})$ and small $(O)$ motoneurons were cultured in the presence of the indicated dilutions of muscle extract $(100 \%=6 \mathrm{mg} / \mathrm{ml})$.

we labeled their precursors with BrdU at a stage (F.4.5) at which large motoneurons should already be post-mitotic. Embryos received injections of BrdU (100 $\mu$ l of $1 \mathrm{mM})$ at E4.5 and E5.5, and the percentage of large Islet-1-positive motoneurons labeled with BrdU was determined at E5.5 and E7.5. No large motoneurons were labeled in E5.5 spinal cord. In contrast, 3000 large motoneurons per spinal cord were labeled in embryos that had been allowed to mature to E7.5. This demonstrates that many small motoneurons can become large motoneurons in the course of the $3 \mathrm{~d}$ following their birth. To confirm that the precursors of the double-labeled large motoneurons at E7.5 were indeed

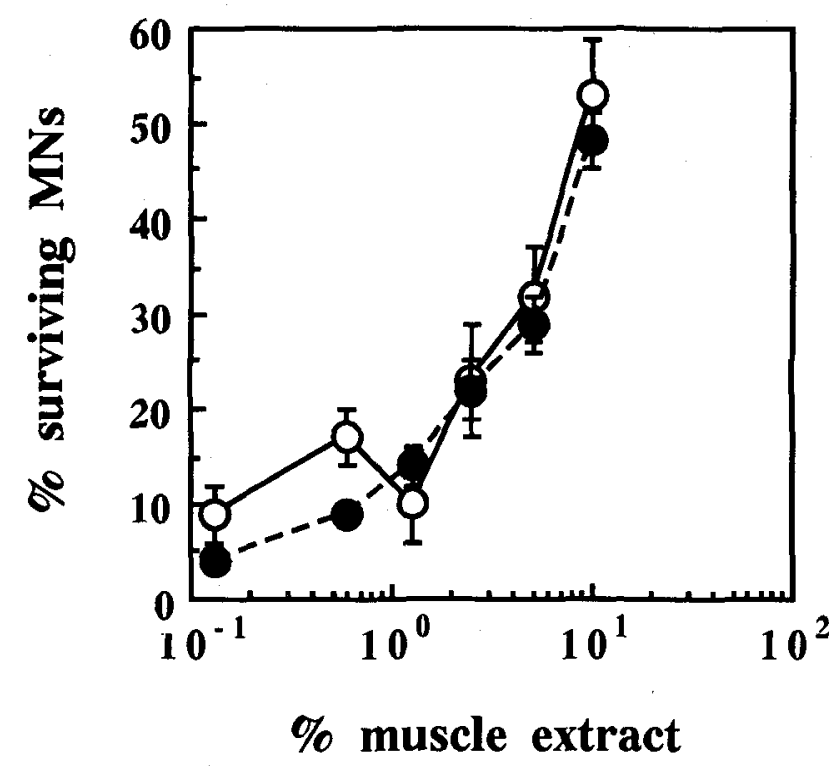

Figure 7. Late-born motoneurons acquire trophic dependence with time in culture. Comparison of the slopes of the dose-response curves of $(\bigcirc)$ small motoneurons after $3 \mathrm{~d}$ in culture and $(O)$ large motoneurons after $2 \mathrm{~d}$ in culture. Results are means $\pm \operatorname{SEM}(n=6)$.

small motoneurons, we performed the same experiment except that BrdU injection was started at E5, too late to label a significant proportion of the small population (see Fig. 4). In these conditions, no BrdU labeling was detected in the population of large motoneurons at E7.5.

\section{Discussion}

The combination of a method based on density (metrizamide) with another based on antigenic specificity (panning on SC1 antibody) has allowed us to isolate two distinct populations of motoneuron from spinal cords of $5 \mathrm{~d}$ chicken embryos, in which the period of naturally occurring cell death is about to begin. The large early-born motoneurons are functionally more mature and have an acute requirement for muscle extract, whereas the small newly postmitotic motoneurons die only slowly in its absence.

Our data suggest that the first motoneurons born in ovo are likely to be among the first to die, and that late-born motoneurons are lost only toward the end of the cell death period. In other words, the sequential birth of motoneurons in a given segment is likely to be mirrored later by death of half of them in roughly the same order. Although in vivo data that address this question are not available, the potential consequences of such a pattern are considerable. Within the lumbar motor column, for instance, motoneurons destined to innervate the ventral muscle mass are born before the dorsally projecting population ( $\mathrm{Hol}-$ lyday and Hamburger, 1977; Landmesser, 1978b). Therefore, it is likely that competition for trophic support from the muscle occurs at an earlier stage in the ventrally projecting pool than in the dorsally projecting group. If muscle (or other tissues) produces different neurotrophic factors at different stages, then the survival of these two apparently similar populations may be controlled by quite different mechanisms. Indirect support for this idea comes from the observation that application in ovo of the neurotrophin BDNF is effective in saving motoneurons only during the second half of the cell death period ( $R$. W. Oppenheim, personal communication). 
Our results are consistent with the view that the small newly postmitotic motoneurons represent a normal intermediate stage in the development of the more mature population purified as large motoneurons. The strongest evidence for this is that a population of motoneurons that are born after E4.5 and still small at E5 copurified $2.5 \mathrm{~d}$ later with the large motoneuron population. Because of the variability in yield inherent in the multistep purification protocol, and because the percentage of small motoneurons labeled by late BrdU injections is exquisitely sensitive to individual embryo age (Fig. 4), it was not possible to determine whether the developmental conversion of small to large motoneurons was quantitative. However, the 3000 double-labeled large motoneurons per spinal cord found at E7.5, representing approximately $10 \%$ of the small motoneurons at E5.5, are within the range expected $(0-40 \%$; see Fig. 4$)$ if the smalllarge transition concerned the whole motoneuron population. Furthermore, our in vitro results (Fig. 7) suggest that the size transition is accompanied by a change of functional trophic requirements with time. The alternative would be that late-born motoneurons represent a distinct subpopulation by their size, biochemical properties, and late onset of trophic dependence. However, no bimodal distribution in the size of dying motoneurons has been described (Oppenheim et al., 1975). Moreover, we found similar proportions of large and small motoneurons at all rostrocaudal levels (Table 1), demonstrating that small motoneurons are not a specialized subpopulation (nor are they the preganglionic neurons of the column of Terni which also express SC1 and Islet-1 but are absent from limb segments) (Tanaka and Obata, 1984; Oppenheim et al., 1989; Ericson et al., 1992). Developmental increases in size, ChAT levels, and p 75 expression are part of the normal properties of the majority of motoneurons (Oppenheim et al., 1975; Yan and Johnson, 1987; Phelps et al., 1990). We therefore favor the idea that each motoneuron subpopulation requires a period of maturation after the last mitosis before becoming dependent on muscle-derived factors. These developmental stages may correspond to the developmental phases I, II, and III defined by Prestige (1967) for Xenopus motoneurons on the basis of their response to limb amputation.

A similar phenomenon has been described for embryonic sensory neurons. Neurons of the geniculate, petrosal, and nodose ganglia isolated at early postmitotic stages survive for periods of several days in the absence of trophic support, before becoming dependent on BDNF (Vogel and Davies, 1991). In accordance with our observation for small and large motoneurons (Fig. 6), the rate at which each population dies is characteristic. The earliest time of response to BDNF varies by about $2 \mathrm{~d}$ between vestibular and nodose ganglia, which show the greatest difference. In the sensory system, the distinct localization of each population allows a further correlation to be made: neurons that in vivo take longer to reach their target survive longer in vitro before responding to BDNF (Vogel and Davies, 1991). No comparable data exist concerning the very early stages of muscle innervation by motoneurons, and interpretation is complicated by the fact that motor axons wait for some time at the base of the limb before invading the developing muscle masses (Hollyday, 1980), but it is tempting to speculate that the period of trophic independence corresponds to the period necessary for target innervation. Indeed, although some axons have left the spinal cord at both brachial and lumbar levels as early as E4 (Fouvet, 1973), the majority grow out over the next $36 \mathrm{hr}$ (Landmesser, 1980), so that the number of axons in the ventral root swells from 800 to 5500 over this period (Chu-Wang and Op- penheim, 1978). By E5.5, essentially all motoneurons can be labeled by retrograde transport from the limb muscles (Oppenheim and Chu-Wang, 1977), and some have formed primitive functional contacts with their target muscle (Landmesser, 1978a).

Metrizamide density gradients were first introduced as a method for enriching motoneurons by Schnaar and Schaffner (1981). Using a modification of this technique with E6 chicken embryos, Dohrmann et al. (1986) estimated motoneuron abundance in the metrizamide fraction to be $>95 \%$, based on extrapolation from a value of $24 \%$ neurons labeled by retrograde transport of rhodamine from the limb. Our results using the motoneuron markers $\mathrm{SC} 1$ and Islet-1 suggest that the true figure may be closer to $50 \%$ at E6. Based on our analysis of cell size distribution in spinal cord dissociates (Fig. 1), we used metrizamide cushions at earlier developmental stages. At E5, large neurons are recovered by this procedure in reasonable yield and with excellent one-step enrichment $(>80 \%)$ for motoneurons, as also recently demonstrated by Comella et al. (1994). The simplicity of the dissection, the rapidity of the procedure, and the lack of requirement for specific reagents or apparatus make it probably preferable to both the method of Arakawa et al. (1990) and to our panning procedure (Bloch-Gallego et al., 1991) for routine applications requiring a homogeneous population of E5 motoneurons that are completely free of non-neuronal cells.

Motoneuron survival in vivo is regulated by both intrinsic and extrinsic factors. Among the former, we may count the acquisition of trophic dependence and the timing of cell death, whereas obvious examples of the latter are the muscle-derived trophic factors that still have clearly to be defined, especially in the chick. However, interactions between the two types of influence are considerably more complex. One example concerns motoneurons innervating wing and leg muscles. Although the first axons invade wing and leg at similar stages (Fouvet, 1973), and both populations acquire trophic dependence at E6 (Laing, 1982), cell death in the brachial motor column does not start until E8 (Hamburger, 1975; Oppenheim and Majors-Willard, 1978; Laing, 1982), at which stage death in the lumbar column is more than half complete. This may in part be determined by intrinsic differences in the response of each population to extrinsic muscle-derived factors (Mettling et al., 1993). Another example is that exogenous factors can accelerate maturation of sensory neurons before they become dependent on these factors for survival (Wright et al., 1992). In this context, the novel population of purified newly postmitotic motoneurons described here should be useful for studying the regulation of the processes leading up to the "choice" between death and survival.

\section{References}

Allsopp TE, Robinson M, Wyatt S, Davies AM (1993) Ectopic trkA expression mediates a NGF survival response in NGF-independent sensory neurons but not in parasympathetic neurons. J Cell Biol 123: $1555-1566$

Arakawa Y, Sendtner M, Thoenen H (1990) Survival effect of ciliary neurotrophic factor (CNTF) on chick embryonic motoneurons in culture: comparison with other neurotrophic factors and cytokines. $\mathbf{J}$ Neurosci 10:3507-3515.

Bloch-Gallego E, Huchet M, El M'Hamdi H, Xie FK, Tanaka H, Henderson CE (1991) Survival in vitro of motoneurons identified or purified by novel antibody-based methods is selectively enhanced by muscle-derived factors. Development 111:221-232.

Camu W, Bloch-Gallego E, Henderson CE (1993) Purification of spinal motoneurons from chicken and rat embryos by immunopanning. Neuroprotocols 2:191-199.

Chu-Wang W, Oppenheim RW (1978) Cell death of motoneurons in 
the chick embryo spinal cord-II. A quantitative and qualitative analysis of degeneration in the ventral root, including evidence for axon outgrowth and limb innervation prior to cell death. J Comp Neurol $177: 59-86$

Comella JX, Sanz-Rodriguez C, Aldea M, Esquerda JE (1994) Skeletal muscle-derived trophic factors prevent motoneurons from entering an active cell death program in vitro. J Neurosci 14:2674-2686.

Dohrmann U, Edgar D, Sendtner M, Thoenen H (1986) Muscle-derived factors that support survival and promote fiber outgrowth from embryonic chick spinal motor neurons in culture. Dev Biol 118:209221.

Dohrmann U, Edgar D, Thocnen H (1987) Distinct neurotrophic factors from skeletal muscle and the central nervous system interact synergistically to support the survival of cultured embryonic spinal motor neurons. Dev Biol 124:145-152.

Ericson J, Thor S, Edlund T, Jessell TM, Yamada T (1992) Early stages of motor neuron differentiation revealed by expression of homeobox gene Islet-1. Science 256:1555-1560.

Fonnum F (1975) A rapid radiochemical method for the determination of choline acetyltransferase. J Neurochem 24:407-409.

Fouvet B (1973) Innervation et morphogenèse de la patte chez l'embryon de poulet. 1. Mise en place de l'innervation normale. Arch Anat Microsc. Morphol Exp 62:269-280.

Hamburger V (1958) Regression versus peripheral control of differentiation in motor hypoplasia. Am J Anat 102:365-410.

Hamburger V (1975) Cell death in the development of the lateral motor column of the chick embryo. J Comp Neurol 160:535-546.

Hamburger V (1977) The developmental history of the motor neuron. Neurosci Res Program Bull 15S:1-37.

Henderson CE, Huchet M, Changeux JP (1983) Denervation increases a neurite-promoting activity in extracts of skeletal muscle. Nature 302:609-611.

Henderson CE, Camu W, Mettling C, Gouin A, Poulsen K, Karihaloo M, Rullamas J, Evans T, McMahon SB, Armanini M, Berkemeier L, Phillips H, Rosenthal A (1993) Neurotrophins promote motor neuron survival and are present in embryonic limb bud. Nature 363:266270 .

Hollyday M (1980) Motoneuron histogenesis and the development of limb innervation. Curr Top Dev Biol 15:181-215.

Hollyday M, Hamburger V (1977) An autoradiographic study of the formation of the lateral motor column in the chick embryo. Brain Res 132:197-208.

Laing NG (1982) Timing of motoneuron death in the brachial and lumbar regions of the chick embryo. Brain Res 5:181-186.

Landmesser L (1978a) The development of motor projection patterns in the chick hind limb. J Physiol (Lond) 284:391-414.

Landmesser L (1978b) The distribution of motoneurons supplying chick hind limb muscles. J Physiol (Lond) 284:37.1-389.

Landmesser L (1980) The generation of neuromuscular specificity. Annu Rev Neurosci 3:279-302.

Mettling C, Camu W, Henderson CF (1993) Fmbryonic wing and leg motoneurons have intrinsically different survival properties. Development 118:1149-1156.
Oppenheim RW (1989) The neurotrophic theory and naturally occurring motoneuron death. Trends Neurosci 12:252-255.

Oppenheim RW, Chu-Wang W (1977) Spontaneous cell death of spinal motoneurons following peripheral innervation in the chick embryo. Brain Res 125:154-160.

Oppenheim RW, Majors-Willard C (1978) Neuronal cell death in the brachial spinal cord of the chick is unrelated to the loss of polyneuronal innervation in wing muscle. Brain Res 154:148-152.

Oppenheim RW, Chu-Wang W, Foelix RF (1975) Some aspects of synaptogenesis in the spinal cord of the chick embryo: a quantitative electron microscopic study. J Comp Neurol 161:383-418.

Oppenheim RW, Chu-Wang IW, Madcrdrut JL (1978) Ccll death of motoneurons in the chick embryo spinal cord. III. The differentiation of motoneurons prior to their induced degeneration following limbbud removal. J Comp Neurol 177:87-112.

Oppenheim RW, Cole T, Prevette D (1989) Early regional variations in motoneuron numbers arise by differential proliferation in the chick embryo spinal cord. Dev Biol 133:468-474.

Oppenheim RW, Yin QW, Prevette D, Yan Q (1992) Brain-derived neurotrophic factor rescues developing avian motoneurons from cell death. Nature 360:755-757.

Oppenheim RW, Prevette D, Haverkamp LJ, Houenou L, Yin Q-W, McManaman J (1993) Biological studies of a putative avian-musclederived neurotrophic factor that prevents naturally-occurring cell death in vivo. J Neurobiol 24:1065-1079.

Phclps PE, Barber RP, Brennan LA, Maines VM, Salvaterra PM, Vaughn JE (1990) Embryonic development of four different subsets of cholinergic neurons in rat cervical spinal cord. J Comp Neurol 291:9-26.

Raivich G, Zimmermann A, Sutter A (1985) The spatial and temporal pattern of $\beta$ NGF receptor expression in the developing chick embryo. EMBO J 4:637-644.

Schnaar RL, Schaffner AE (1981) Separation of çell types from embryonic chicken and rat spinal cord: characterization of motoneuronenriched fractions. J Neurosci 1:204-217.

Tanaka H, Obata K (1984) Developmental changes in unique cell surface antigens of chick embryo spinal motoneurons and ganglion cells. Dev Biol 106:26-37.

Tanaka H, Agata A, Obata K (1989) A new membrane antigen revealed by monoclonal antibodies is associated with motoneuron axonal pathways. Dev Biol 132:419-435.

Vogel KS, Davies AM (1991) The duration of neurotrophic factor independence in early sensory neurons is matched to the time course of target field innervation. Neuron 7:819-830.

Wright EM, Vogel KS, Davies AM (1992) Neurotrophic factors promote the maturation of developing sensory neurons before they become dependent on these factors for survival. Neuron 9:139-150.

Yamada T, Pfaff SL, Edlund T, Jessell TM (1993) Control of cell pattern in the neural tube: motor neuron induction by diffusible factors from notochord and floor plate. Cell 73:673-686.

Yan Q, Johnson EM (1987) A quantitative study of the developmental expression of nerve growth factor (NGF) receptor in rats. Dev Biol 121:139-148. 